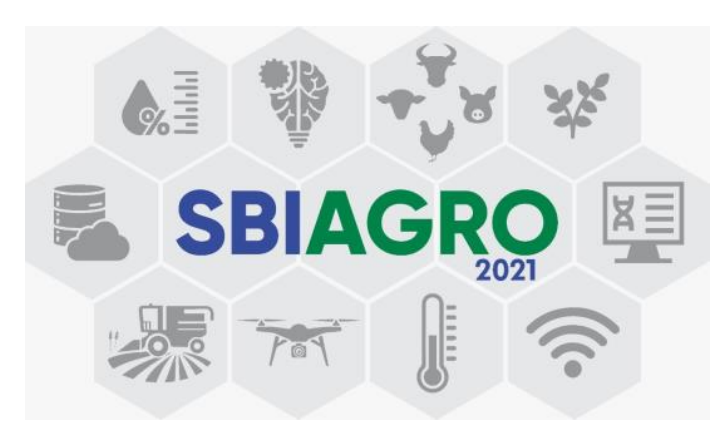

\title{
CanControl: plataforma para diagnóstico do Cancro Europeu da Macieira
}

\author{
Wilson C. Branco Netoํ, Leonardo Araújo², Felipe A. M. Ferreira Pinto², \\ Rodrigo A. Machado ${ }^{3}$, Yan F. B. Ribeiro ${ }^{3}$, Wilson F. Cordova Junior ${ }^{3}$, \\ Kevin Mondadori Mattos ${ }^{3}$
}

${ }^{1}$ Depto. de Ensino, Pesquisa e Extensão - Instituto Federal de Santa Catarina (IFSC). Lages - SC - Brasil.

${ }^{2}$ Estação Experimental de São Joaquim - Empresa de Pesquisa Agropecuária e Extensão Rural de Santa Catarina (Epagri). São Joaquim - SC - Brasil.

${ }^{3}$ Curso de Ciência da Computação - Instituto Federal de Santa Catarina (IFSC). Lages - SC - Brasil.



\begin{abstract}
This paper presents a platform created to publish information about Apple Canker and facilitate the diagnosis and monitoring of infected plants. It is made up of an API, a web system and a mobile application, which enable farmers to register suspicious plants and Epagri phytopathologists to remotely diagnose them. The application has been available since June of 2021 and has already been downloaded 110 times, 25 producers have registered themselves in the system and registered 23 suspicious plants
\end{abstract}

Resumo. Este artigo apresenta uma plataforma criada para divulgar informações sobre o Cancro Europeu da Macieira e facilitar o diagnóstico e monitoramento das plantas infectadas. Ela é composta por uma API, um sistema web e um aplicativo móvel, que possibilitam que os produtores cadastrem plantas suspeitas e os Fitopatologistas da Epagri realizem o diagnóstico de forma remota. $O$ aplicativo está disponível desde junho de 2021 e já conta com 110 downloads, 25 produtores realizaram seu cadastro no sistema e registraram 23 plantas suspeitas. 


\section{Introdução}

O Cancro Europeu da Macieira (CEM), causado por Neonectria ditissima, é uma importante doença que atinge pomares em várias regiões do mundo [Weber 2014]. No Brasil, a presença da doença foi constatada pela primeira vez em 2002 em um viveiro no Rio Grande de Sul e, aproximadamente dez anos depois, iniciaram os registros da doença em diversos pomares comerciais do Rio Grande do Sul e de Santa Catarina [Alves e Czermainski 2015].

Segundo Lazzarotto e Alves (2015), "nas condições ambientais brasileiras, a doença tem se manifestado de maneira bastante agressiva", acarretando prejuízos em curto, médio e longo prazo. Os mesmos autores afirmam que o CEM pode inviabilizar a produção de maçãs nas regiões atingidas e projetam os resultados econômicos de quatro cenários distintos em relação ao nível de infecção e às medidas de controle adotadas:

- Cenário 1 - sem incidência: a lucratividade de um pomar é de $21,91 \%$ e sua vida útil de 20 anos;

- Cenário 2 - incidência baixa: a lucratividade cai para 17,33\% e a vida útil permanece em 20 anos;

- Cenário 3 - incidência média a alta com medidas de controle: a vida útil permanece em 20 anos, mas a lucratividade cai para 8,86\% em função do alto custo para controle da doença, bem como da redução de produtividade;

- Cenário 4 - incidência média a alta sem medidas de controle: além da lucratividade cair para 5,57\%, a vida útil do pomar é de apenas 12 anos.

Devido à gravidade da situação, o Ministério da Agricultura Pecuária e Abastecimento publicou a instrução normativa - IN 20, de 20/06/2013 [Brasil 2013], que foi atualizada pela portaria 319 , de 26/05/2021. Esta portaria, em seu artigo $1^{\text {o, }}$ define como objetivo "Instituir o Programa Nacional de Prevenção e Controle do Cancro Europeu - PNCE, cujo agente etiológico é o fungo N. ditissima” [Brasil 2021].

A portaria estabelece, entre outros pontos, as medidas que devem ser adotadas pelos produtores e entidades envolvidas. Merecem destaque dois artigos. $\mathrm{O}$ artigo $13^{\circ}$ determina que em Unidades de Produção (UP) com incidência de até 5\% de plantas infectadas, as plantas com sintomas deverão ser arrancadas e incineradas, e as plantas vizinhas marcadas e vistoriadas mensalmente. O artigo $14^{\circ}$ estabelece que nas UP com incidência superior a $5 \%$ de plantas infectadas, deverão ser realizados procedimentos para prevenção e controle do CEM, tais como a eliminação e incineração de partes da planta ou a limpeza e tratamento do mesmo [Brasil 2013].

Além das normativas federais, o Governo do Estado de Santa Catarina sancionou a lei 17.825/2019 [Santa Catarina 2019]. Dentre outros aspectos, esta lei determina como deve ser feita a fiscalização das propriedades e as penalidades previstas, como demonstra o "Art. 22. Sem prejuízo das responsabilidades penal, ambiental e civil cabíveis, fica o infrator sujeito às seguintes penalidades, aplicadas de maneira isolada ou cumulativa: I - Advertência; II - Multa; e III - Suspensão ou cancelamento de autorizações, registros, inscrições, credenciamentos, cadastros, habilitações, certificados ou documentos de trânsito.

Com a obrigatoriedade da fiscalização e as penalidades impostas por esta lei, pretende-se evitar que o CEM se dissemine em Santa Catarina como aconteceu no Rio 
Grande do Sul, pois a situação da incidência da doença nos pomares difere nos dois principais estados produtores de maçã no Brasil.

No Rio Grande do Sul, segundo a Secretaria de Estado de Agricultura, Pecuária e Irrigação (SEAPI), 51\% das propriedades já apresentam plantas infectadas. Um levantamento realizado em 277 propriedades, entre 2015 e 2016, mostrou que aproximadamente $60 \%$ destas já possuíam incidência superior a $1 \%$ do total de plantas, o que desobrigava os produtores a arrancarem e incinerarem as plantas, pois este era o percentual definido pela IN 20/2013 vigente na época [Araujo et al. 2019]. A incidência da doença no estado de Santa Catarina é menor. Conforme dados da CIDASC (Companhia Integrada de Desenvolvimento Agrícola de Santa Catarina), apresentados por Araujo et al. (2019), aproximadamente $10 \%$ das unidades produtivas já tiveram registro de ocorrência do CEM, destas, $93 \%$ possuíam menos de $1 \%$ de incidência da doença nos pomares.

Em função destas diferenças, a Epagri (Empresa de Pesquisa Agropecuária e Extensão Rural de Santa Catarina) e a CIDASC trabalham na tentativa de erradicação ou de manutenção dos baixos índices de incidência da doença no estado. Para que estes objetivos sejam alcançados, é fundamental realizar a diagnose de forma correta e o mais cedo possível. No entanto, no processo de identificação do CEM nos pomares, muitos técnicos e fruticultores podem ficar em dúvida se a lesão encontrada em uma macieira é causada por $N$. ditíssima ou não, devido ao processo de diagnose adotado.

Atualmente, o diagnóstico é realizado de forma empírica pelos produtores e responsáveis técnicos, os quais, em caso de dúvida, coletam material e enviam para análise na Estação Experimental de São Joaquim (Epagri-EESJ). A falta de conhecimento para um diagnóstico preciso a campo e a necessidade de deslocamento para análise do material suspeito pode levar a diagnósticos incorretos ou, até mesmo, a sua não efetivação. Por isto, o desenvolvimento de tecnologias que viabilizem um diagnóstico mais rápido e fácil é importante porque possibilita que a planta seja erradicada antes que ocorra a disseminação da doença para outras macieiras saudáveis.

Este artigo apresenta uma plataforma desenvolvida em um projeto realizado em parceria entre o Instituto Federal de Santa Catarina (IFSC) e a Epagri, com o objetivo de auxiliar os produtores e responsáveis técnicos a realizar o diagnóstico correto, assim como difundir o conhecimento existente sobre a doença.

\section{Materiais e Métodos}

Para atingir os objetivos propostos, foram desenvolvidos três sistemas, como pode ser visto na Figura 1, para atender dois perfis de usuários: 1) Produtores/ Responsáveis Técnicos; 2) Fitopatologistas da Epagri-EESJ. Os produtores e responsáveis técnicos utilizam o aplicativo móvel para efetuar o seu cadastro no sistema e registrar plantas com suspeita de infecção. Os fitopatologistas da Epagri-EESJ, por meio do sistema web, analisam os registros feitos e emitem o diagnóstico. Além das funcionalidades relacionadas ao diagnóstico das plantas, tanto o aplicativo móvel quanto o sistema web apresentam um conjunto de informações em formato de textos, fotos e vídeos que visam difundir o conhecimento sobre a doença. 




Aplicativo

Figura 1. Arquitetura da plataforma

O banco de dados que armazena as informações dos produtores e responsáveis técnicos cadastradas, bem como os monitoramentos realizados por eles, foi desenvolvido em PostgreSQL. A API foi construída em JavaScript, sendo executada sobre o NodeJS. Na API estão implementados todos os métodos de acesso ao banco de dados, a lógica de negócio e os aspectos de segurança. A versão disponível do aplicativo móvel foi desenvolvida em Kotlin e, por isto, pode ser executada apenas em dispositivos com o sistema Android. Uma nova versão do aplicativo móvel está sendo desenvolvida em Flutter para atender os usuários que possuem o sistema IOS. O sistema web foi construído usando o framework Vue.js.

\subsection{Aplicativo móvel}

As funcionalidades do aplicativo móvel estão organizadas em quatro seções: Informações, Fotos, Videos e Monitorar. A seção de Informações apresenta textos explicativos sobre a doença, sintomas, disseminação, estratégias de controle etc., produzidos pelos fitopatologistas da Epagri-EESJ. A Figura 2 apresenta a interface desta seção com os tópicos informativos sobre a doença (2a); ao clicar sobre um deles, uma página é aberta com o texto e imagens (2b); e ao clicar sobre uma das imagens é possível ampliá-la para uma análise detalhada $(2 \mathrm{c})$.

O aplicativo também possui uma seção com imagens que apresentam lesões em diferentes partes da planta causadas pelo CEM e, também, por outras doenças com sintomas semelhantes para que o usuário consiga diferenciá-las. A Figura 3 apresenta a interface com a lista de categorias de imagens (3a); ao clicar sobre uma das categorias são apresentadas miniaturas das imagens daquela categoria (3b); por fim, ao clicar sobre uma das imagens é possível visualizá-la ampliada, bem como aplicar zoom a ela para analisá-la em detalhes de forma semelhante ao apresentado na Figura 2(c).

Além dos textos e imagens, o aplicativo apresenta vídeos que explicam diferentes aspectos da doença e demonstram como realizar o diagnóstico a partir de sintomas nas diferentes partes da planta e em diferentes estádios fenológicos. A Figura 3(c) apresenta parte da lista com os vídeos disponíveis. De forma semelhante à seção de informações, a obtenção e seleção das imagens e a produção dos vídeos foram realizadas pelos fitopatologistas da Epagri-EESJ. 

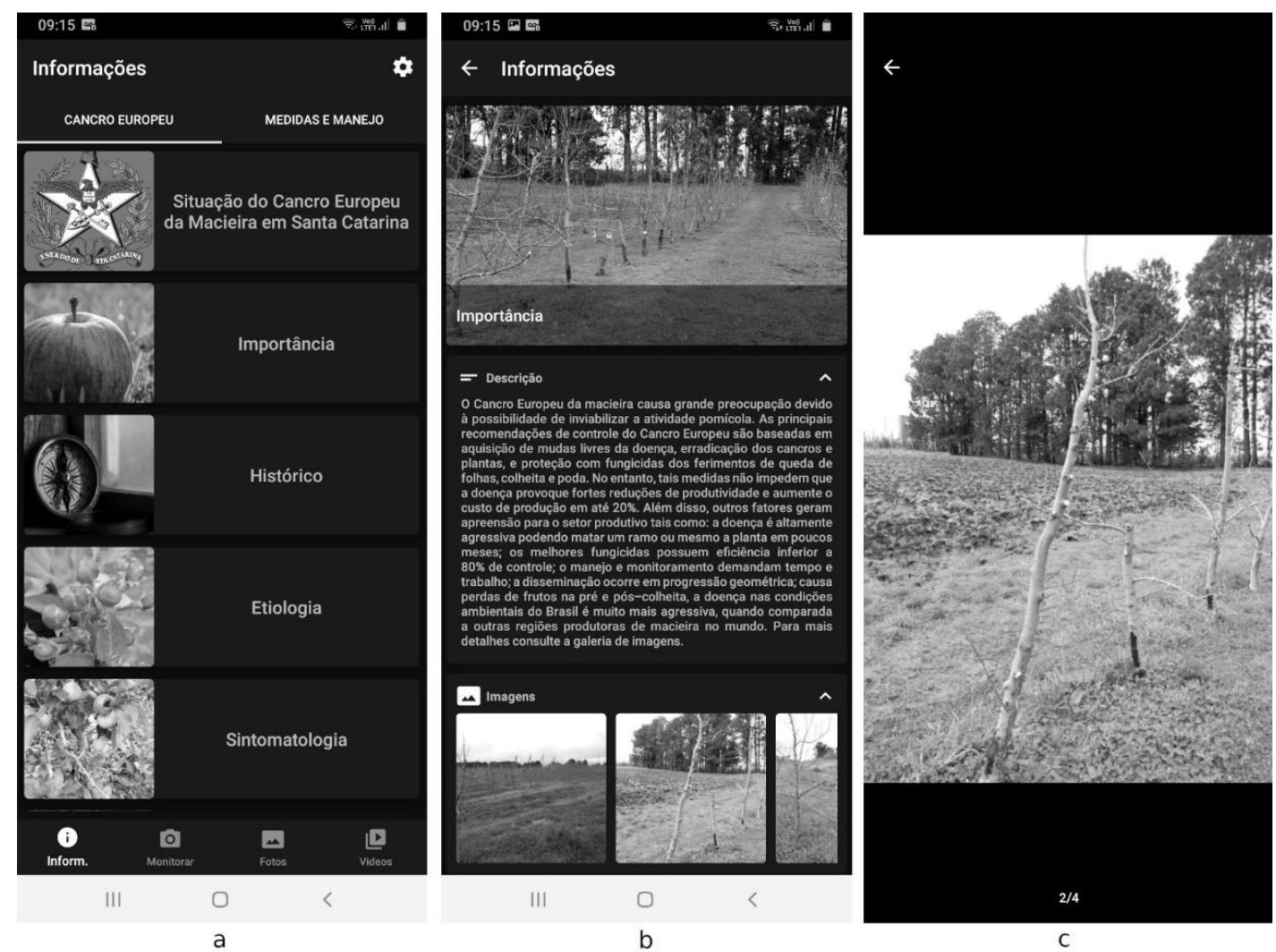

Figura 2. Interface do aplicativo móvel - Informações
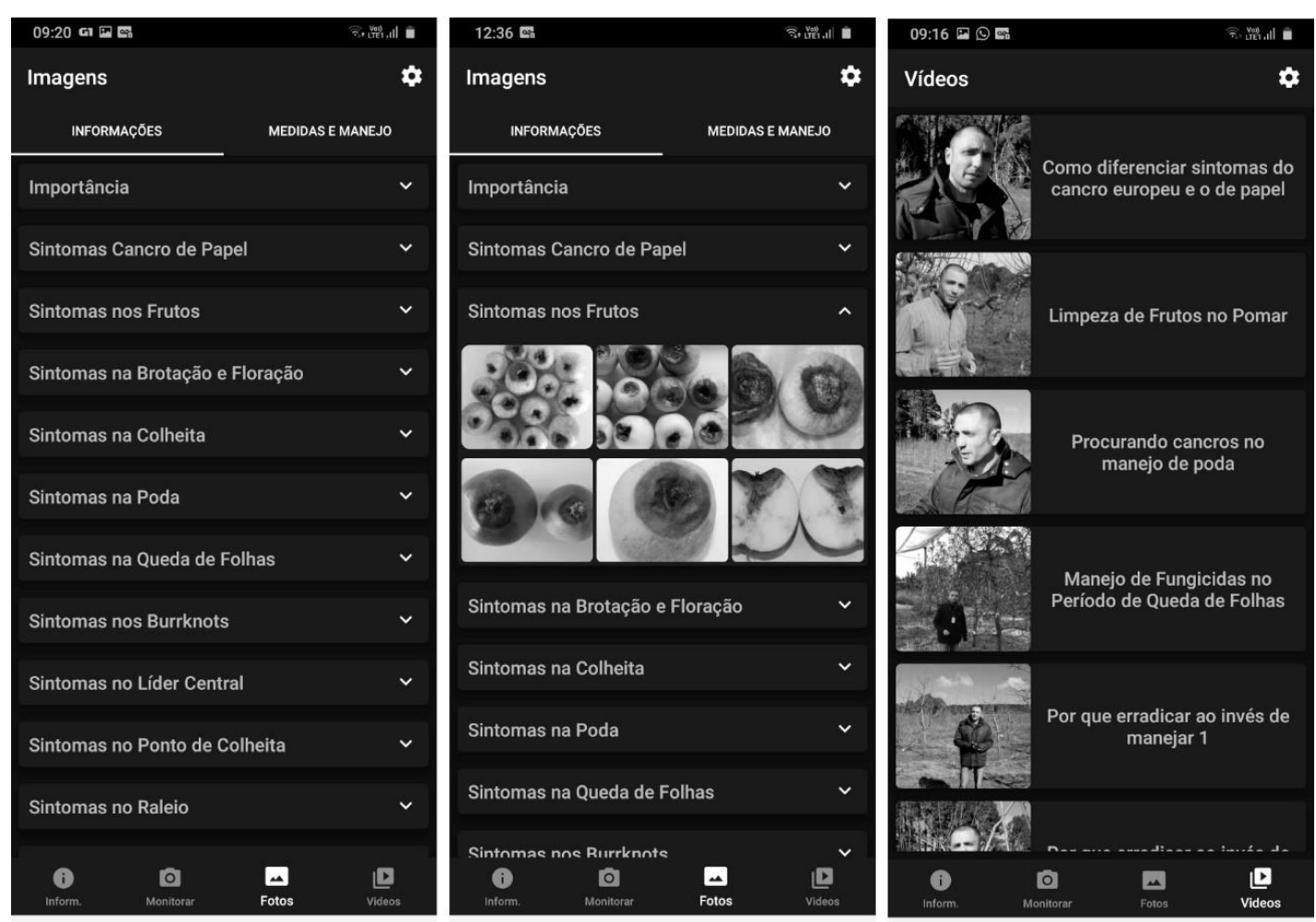

○

III 0

b

Figura 3. Interface do aplicativo móvel - Imagens e Vídeos 
Outra funcionalidade do aplicativo móvel é a seção de monitoramento apresentada na Figura 4. Ela permite que o usuário cadastre os monitoramentos realizados, preenchendo os dados solicitados e registrando as imagens da planta (4a); que ele acompanhe e visualize o resultado do diagnóstico emitido pelos pesquisadores da Epagri (4b); e que ele localize a planta infectada por meio de suas coordenadas geográficas $(4 \mathrm{c})$ para arrancá-la e incinerá-la caso o diagnóstico seja positivo.

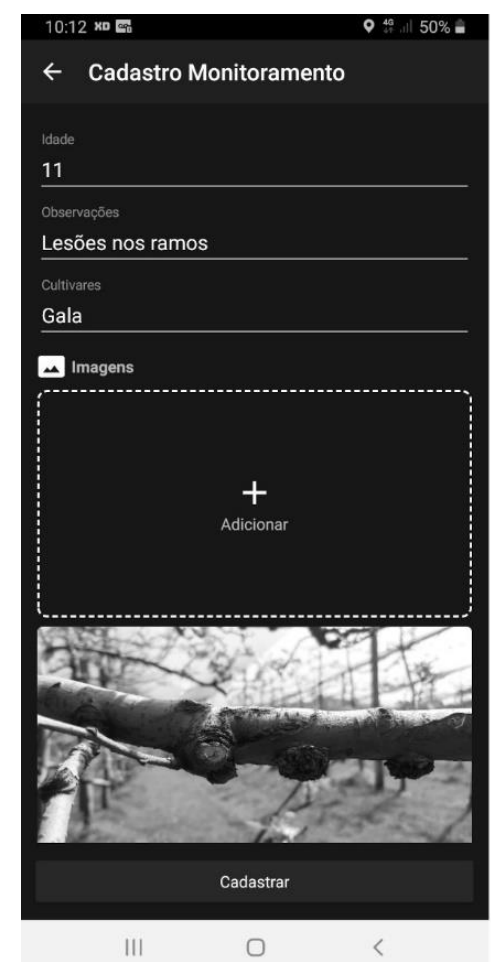

(a)

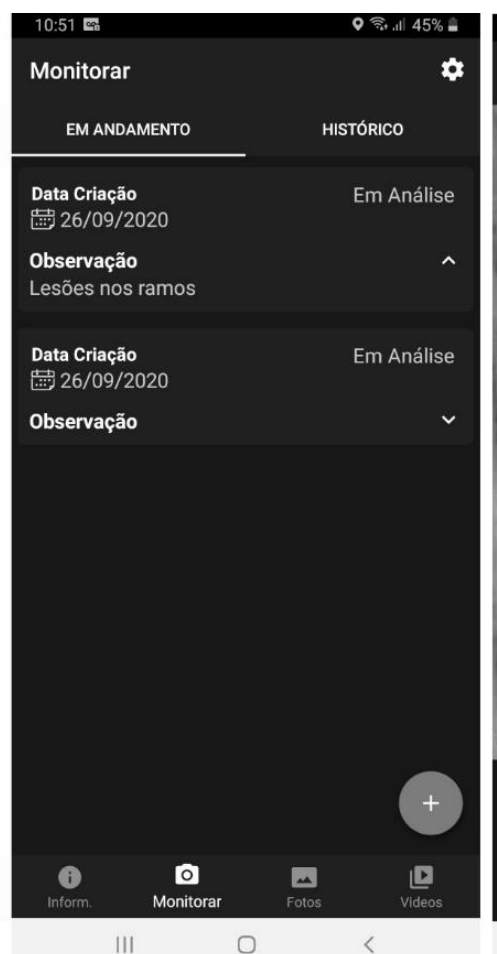

(b)

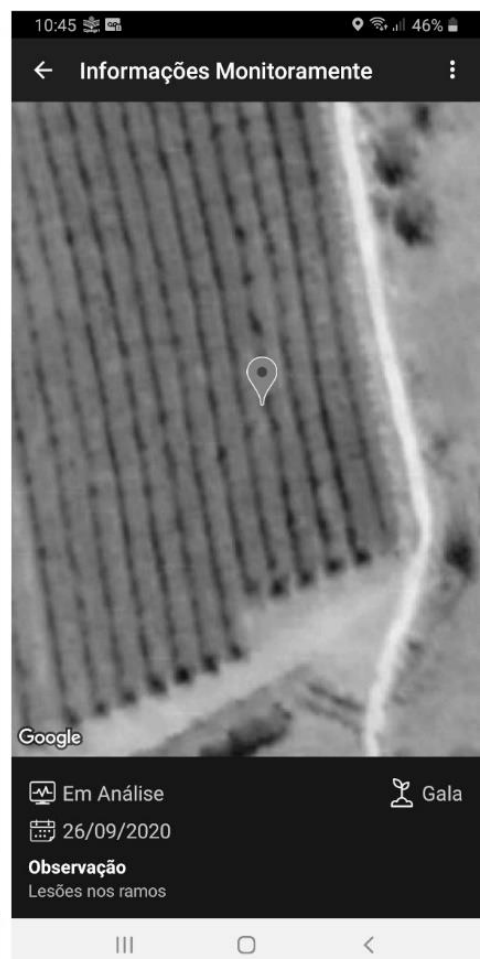

(c)

Figura 4. Interface do aplicativo móvel - Monitoramento

Apesar do aumento da cobertura da Internet nas áreas rurais do Brasil, ainda existem muitas regiões que não possuem conexão à rede. Por isto, o aplicativo móvel foi desenvolvido para funcionar offline. O produtor tem acesso a todos os textos explicativos e fotos, e pode fazer o seu cadastro e o registro de plantas suspeitas mesmo desconectado da Internet. Ao retornar a um ponto com acesso à Internet, o sistema conecta-se à API e sincroniza os dados registrados automaticamente. A única função do sistema que não funciona offline é a de vídeos, pois eles estão armazenados no Youtube e não no aplicativo para não sobrecarregar o dispositivo dos usuários.

Também com o intuito de melhorar a usabilidade do sistema, foi criado um mecanismo de notificação para avisar o usuário quando os fitopatologistas emitem o diagnóstico do monitoramento registrado por ele, evitando que ele precise ficar entrando no aplicativo para verificar se a resposta já foi enviada ou não.

\subsection{Sistema Web}

O sistema web foi desenvolvido para que os fitopatologistas possam analisar os monitoramentos enviados pelos produtores. Além disto, ele apresenta as mesmas 
informações sobre o CEM para os produtores e responsáveis técnicos que prefiram usálo para visualizar os textos, fotos e vídeos. Ele também possibilita que os fitopatologistas da Epagri, mediante login e senha, visualizem um mapa georreferenciado dos casos registrados, para auxiliar as instituições responsáveis pelo monitoramento e fiscalização da doença.

A interface inicial do site apresenta um menu que leva às seções de Informações, Imagens, Vídeos e Arquivos. As três primeiras possuem as mesmas informações disponíveis no aplicativo e a última contempla documentos tais como legislações, artigos científicos, boletins epidemiológicos, dentre outros, que não foram incorporados ao aplicativo para reduzir seu tamanho.

Por meio da opção Login, os pesquisadores da Epagri têm acesso à parte interna do site que apresenta os monitoramentos realizados pelos diferentes produtores e responsáveis técnicos. Ao clicar sobre um dos monitoramentos da lista, o sistema apresenta as informações detalhadas e as imagens para que o diagnóstico possa ser emitido, por meio da interface apresentada na Figura 5.

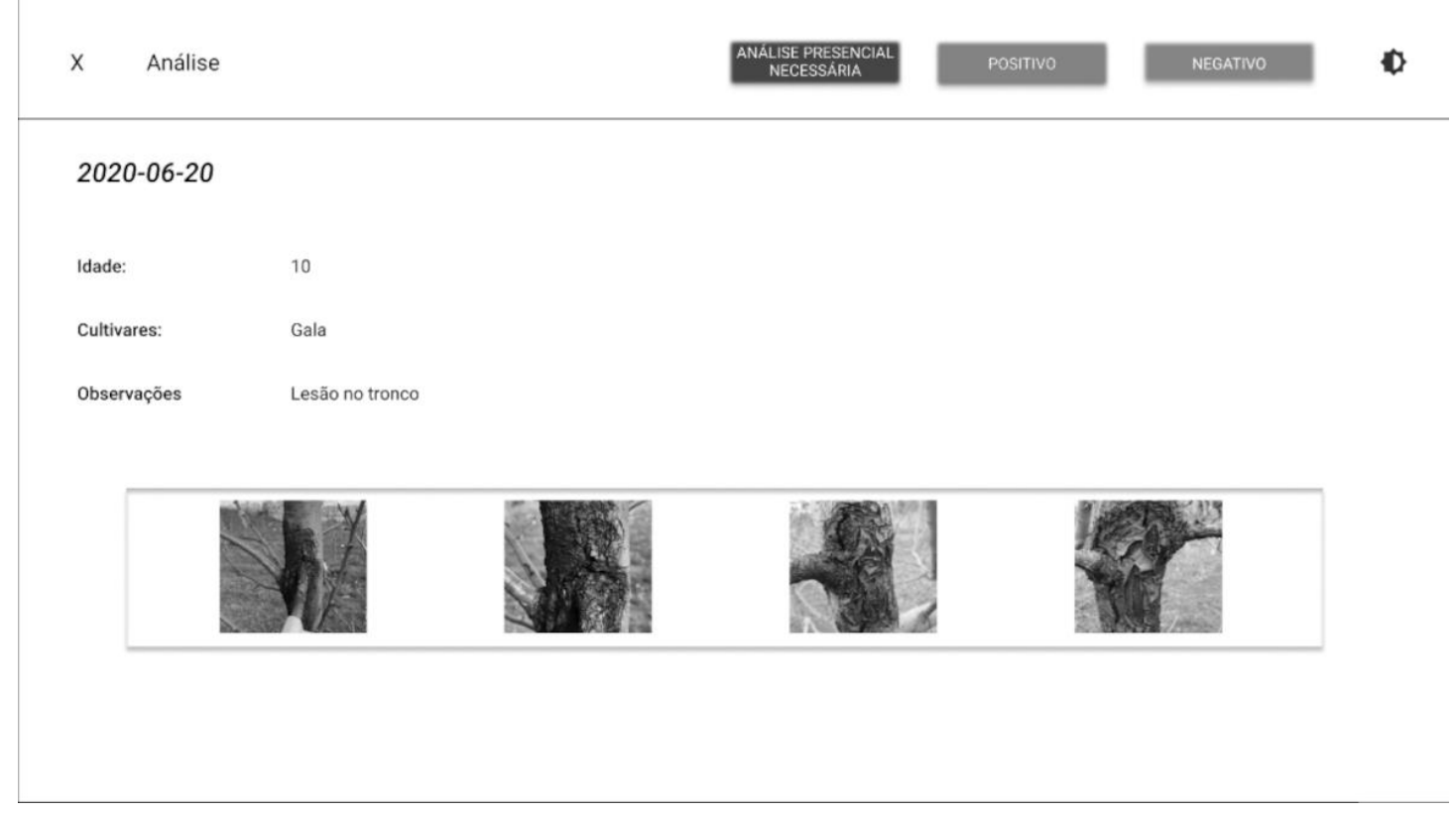

Figura 5. Interface para análise e realização do diagnóstico

O resultado do diagnóstico pode ser:

- Positivo, quando é possível identificar, por meio das fotos cadastradas pelos produtores e responsáveis técnicos, que se trata do CEM;

- Negativo, quando é possível descartar a doença, com base nas imagens enviadas;

- Análise Presencial Necessária, quando não é possível concluir o diagnóstico a partir das fotos. Neste caso, o produtor deve manter a prática atual e enviar o material para análise junto à Clínica Fitopatológica da Epagri-EESJ. 


\section{Resultados e Discussão}

O aplicativo Android foi disponibilizado na Google Play ${ }^{1}$ no dia 02 de junho de 2021 e até o momento atingiu a marca de 110 downloads. Dos usuários que instalaram o aplicativo, 25 já realizaram o seu cadastro e 23 monitoramentos foram registrados. Destes monitoramentos, 9 foram diagnosticados como Positivo, 10 como Negativo e 4 como Análise Presencial Necessária, o que demonstra a capacidade da plataforma desenvolvida para reduzir o tempo para realização da maioria dos diagnósticos e evitar o deslocamento físico até a Epagri-EESJ (19 de 23 casos). O sistema web está temporariamente disponível em um servidor do IFSC ${ }^{2}$, mas uma parceria recém firmada entre IFSC, Epagri e ABPM (Associação Brasileira dos Produtores de Maçã), garantiu recursos para que ele seja transferido para um servidor privado, com domínio próprio a ser registrado em breve.

Estes números devem crescer nos próximos meses, pois os fitopatologistas da Epagri-EESJ estão elaborando material e planejando ações de divulgação junto aos produtores e responsáveis técnicos pelas propriedades. A publicação da versão IOS, prevista para setembro de 2021, também deve contribuir para o aumento dos números, pois atingirá um grupo de usuários que não pode se cadastrar e registrar monitoramentos por não ter um dispositivo compatível com o sistema Android.

\section{Conclusões}

Este artigo apresentou os sistemas desenvolvidos para auxiliar na divulgação de informações sobre o CEM, seu diagnóstico e monitoramento. Os textos, fotos e vídeos disponíveis no aplicativo móvel e no site devem elevar o nível de conhecimento dos produtores e responsáveis técnicos, possibilitando que eles consigam diagnosticar corretamente a doença para tomar as medidas definidas nas normatizações relacionadas.

Além disto, a funcionalidade de monitoramento é capaz de aproximar os produtores dos fitopatologistas da Epagri, que são profissionais com maior conhecimento sobre o assunto e capacidade de diagnóstico, nos casos em que a dúvida persista. Desta forma, pretende-se aumentar a quantidade de diagnósticos corretos realizados, ao evitar a análise presencial do material, contribuindo para auxiliar o produtor na tomada de decisão, facilitar o manejo, reduzir a disseminação da doença e a consequente inviabilização da produção de maçãs no sul do Brasil.

Como trabalhos futuros, além da conclusão do aplicativo para iOS e realização das ações de divulgação da plataforma, pretende-se iniciar estudos na área de Redes Neurais para criar um módulo que seja capaz de analisar automaticamente as imagens enviadas e realizar o diagnóstico em parte delas, sem a necessidade de intervenção por parte dos fitopatologistas.

\section{Referências}

Alves, S. A. M. e Czermainski, A. B. (2015), "Síntese descritiva de eventos relacionados ao cancro europeu das pomáceas no Brasil". Nota Técnica Embrapa, Bento Gonçalves.

\footnotetext{
${ }^{1}$ https://play.google.com/store/apps/details?id=br.edu.ifsc.cancontrol

${ }^{2}$ http://www.cancroeuropeu.com.br
} 
Araujo, L., Pinto, F. A. M. F \& Vieira, J. S. (2019), "Situação do Cancro Europeu no Brasil." In: Cancro Europeu no Brasil. Organizado por Alves, S. A. M. e Czermainski, A. B (org). p. 33-41. Brasília: Embrapa.

Brasil. (2013), Ministério da Agricultura, Pecuária e Abastecimento. Instrução normativa n. 20, de 20 de jun. de 2013.

Brasil. (2021), Ministério da Agricultura, Pecuária e Abastecimento. Portaria n. 319, de 26 de maio de 2021.

Lazzarotto, J. J. e Alves , S. A. M. (2015), "Prejuízos Econômicos e Financeiros Associados ao Cancro Europeu em Sistemas de Produção de Maçã de Vacaria, RS”. Comunicado Técnico EMBRAPA, Bento Gonçalves, v. 169, mar. 2015.

Santa Catarina. (2019), Lei estadual $n^{\circ} 17.825$ de 12 de dezembro de 2019. Dispõe sobre a defesa sanitária vegetal no estado e estabelece outras providências. Diário Oficial do Estado de Santa Catarina, Florianópolis, SC, 16 Dez. 2019.

Weber, R. W. S. (2014), "Biology and control of the apple canker fungus Neonectria ditissima (syn. N. galligena) from a Northwestern European perspective". In: Erwerbs-Obstbau, v. 56, n. 3, p. 95-107. 